\title{
Thoughts that breathe, and words that burn: poetic inquiry within health professions education
}

\author{
Megan E. L. Brown (iD) - Martina Kelly (D) - Gabrielle M. Finn (D)
}

Received: 30 November 2020 / Revised: 16 July 2021 / Accepted: 20 July 2021 / Published online: 1 September 2021 (C) The Author(s) 2021

\begin{abstract}
Qualitative inquiry is increasingly popular in health professions education, and there has been a move to solidify processes of analysis to demystify the practice and increase rigour. Whilst important, being bound too heavily by methodological processes potentially represses the imaginative creativity of qualitative expression and interpretation-traditional cornerstones of the approach. Rigid adherence to analytic steps risks leaving no time or space for moments of 'wonder' or emotional responses which facilitate rich engagement. Poetic inquiry, defined as research which uses poetry 'as, in, [or] for inquiry', offers ways to encourage creativity and deep engagement with qualitative data within health professions education. Poetic inquiry attends carefully to participant language, can deepen researcher reflexivity, may increase the emotive impact of research, and promotes an efficiency of qualitative expression through the use of 'razor sharp' language. This A Qualitative Space paper introduces the approach by outlining how it may
\end{abstract}

Supplementary Information The online version of this article (https://doi.org/10.1007/s40037-021-00682-9) contains supplementary material, which is available to authorized users.

\section{E. L. Brown (殴 · G. M. Finn}

Health Professions Education Unit, Hull York Medical

School, University of York, York, UK

hymb2@hyms.ac.uk

M. E. L. Brown

Medical Education Innovation and Research Centre, Imperial College London, London, UK

\section{Kelly}

Department of Family Medicine, Cumming School of Medicine, University of Calgary, Alberta, Canada

\section{G. M. Finn}

School of Medical Sciences, Faculty of Biology, Medicine and Health, The University of Manchester, Manchester, UK be applied to inquiry within health professions education. Approaches to engaging with poetic inquiry are discussed and illustrated using examples from the field's scholarship. Finally, recommendations for interested researchers on how to engage with poetic inquiry are made, including suggestions as to how to poetize existing qualitative research practices.

Keywords Poetic inquiry · Qualitative research · Phenomenology · Health professions education · Medical education · Poetry

A Qualitative Space highlights research approaches that push readers and scholars deeper into qualitative methods and methodologies. Contributors to A Qualitative Space may: advance new ideas about qualitative methodologies, methods, and/or techniques; debate current and historical trends in qualitative research; craft and share nuanced reflections on how data collection methods should be revised or modified; reflect on the epistemological bases of qualitative research; or argue that some qualitative practices should end. Share your thoughts on Twitter using the hashtag: \#aqualspace.

\section{Introduction}

"Poetry is thoughts that breathe, and words that burn"

\section{Thomas Gray}

Poetry is a vehicle for human meaning making. It is part of everyday life which, if you look, you'll find in advertisements, music, even sports cheers. It is not a modern fascination-indeed, poetry likely predates written text [1]. Before humans documented their experiences in a written format, poetry was an 
integral part of communities' oral cultures, used to pass knowledge, history, and stories between generations [2]. Poems condense human experience, and when this experience speaks to you in some way, poetry feels meaningful and important [3]. Given the innate resonance of poetry to the human condition, poems feature within higher education, too. Within health professions education (HPE), poems have been most typically integrated into curricula within medical humanities modules as a way of centering patient narratives, engendering empathy amongst trainees, and facilitating reflective practice [4-6]. Several medical and medical humanities journals publish authors' poems as arts contributions, demonstrating an appetite for poetry as a creative outlet in HPE. Yet, despite the pertinence of poetry to human experience, poetry as a form of research has not been a central topic of HPE conversation. In this article we introduce readers to poetic inquiry and its potential to expand qualitative research within HPE. We start by offering a broad definition of poetic inquiry, consider why it is both necessary and well suited to the field, and situate our exploration within phenomenology. We then progress to outline some approaches to engaging with poetic inquiry and illustrate these approaches using examples from HPE scholarship. Finally, we invite interested readers to consider ways in which they could engage with poetic inquiry, or to consider ways in which they could poetize their existing qualitative research practices.

\section{What is poetic inquiry?}

Poetic inquiry is an arts-based research methodology which treats poetry as a 'vital way to express and learn' by incorporating original poetry into academic research $[7,8]$. Though there is no consensus definition, 'the key feature of poetic inquiry is the use of poetry $a s, i n$, [or] for inquiry' [9], with poetic inquiry employed in diverse ways by researchers to collect data, collect field notes, and represent and reinterpret data [7]. The approach is gaining traction in many social science disciplines, including sociology, psychology, anthropology, and education [10]. Reasons for the use of poetic inquiry include preservation of participant voice [7], to explore the relationship between language and meaning $[11,12]$, to deepen researcher reflexivity [13], and to increase the emotive impact and accessibility of academic research [14] as poetic inquiry can help both researchers and audiences engage more deeply with participant accounts [15]. Additionally, through its attention to language, poetic inquiry is a rigorous approach-it allows 'thoughts [to] breathe'-whilst also promoting an emotive efficiency of qualitative expression which helps 'words [to] burn'. Yet, despite the benefits poetic inquiry can offer qualitative research, it has not received the same degree of focus or enthusiasm within HPE.

\section{Why do we need poetic inquiry?}

Creative deviation from specific analytic qualitative processes is not the norm within HPE. Though approaches such as phenomenology, which seeks to represent the rich and complex nature of participants' lived experiences [16], are becoming increasingly important within HPE, there has been a move to solidify processes of analysis to demystify the practice, and so increase rigor [17]. Whilst an important consideration, we believe the pendulum of data analysis is in danger of swinging too far-from openness to fixity-and qualitative research is at risk of stagnating. Several scholars have noted that qualitative inquiry often tends towards the descriptive, with deep thought regarding the connections between data, and the meaning of these connections wanting [17, 18]. Such deep thought is necessary for approaches which seek to represent the complexity of experiences, such as within interpretative phenomenology [19]. Others have argued that servile adherence to one's data through a rigid set of analytic steps leaves no time or space for moments of 'wonder', surprise, or the emotional responses of the researcher that facilitate rich engagement and interpretation [20-22]. Being bound too heavily by methodological processes represses the imaginative creativity of qualitative expression and interpretation that has traditionally been a cornerstone of the approach $[23,24]$. As we amass increasing levels of knowledge regarding topics such as professional identity formation within HPE, rich, creative qualitative exploration is necessary to advance scholarship in the field and expand understanding regarding the nuances of the process. New ways of scrutinizing old problems may also help further knowledge [25]. We propose that poetry through the medium of poetic inquiry may offer one way in which to restore creativity and deep engagement with qualitative data to qualitative inquiry within medical education.

\section{Poetic inquiry as part of phenomenological inquiry}

As an approach, poetic inquiry is broad and diverse. Scholars have situated their engagement with poetic inquiry within a variety of different qualitative traditions such as phenomenology [26], participatory action research [27], ethnography [28], narrative inquiry [29] and performative inquiry [30]. We suggest that, within HPE research, poetic inquiry finds a natural home as part approach of phenomenology.

Indeed, poetry is essential to phenomenological thought [31]. For Heidegger, thinking is something which only occurs in the company of, or with poetry [32], Van Manen refers to phenomenology itself as a 'poetizing project' [26], whilst Bachelard used poetry to consider the meaning and impact of physical spaces [33]. As researchers immerse themselves in the construction of poetry from data, they open them- 
selves to "what is said, or more accurately to what is unsaid' [32], a necessary condition to unconcealing phenomena which, for interpretative phenomenologists like Heidegger, is synonymous with truth [34, 35]. As Galvin and Todres surmise, 'poetic language emphasizes 'wholeness', in that, through rhythm, repetition, and imagery, a wholeness is pointed to that is more than what is there' [36]. In this way, poetic inquiry facilitates an openness to the otherness of language' [32], and acts as a way of thinking about one's data in a way that engenders moments of wonder, and stimulates deep, analytical thought. Whilst at the heart of phenomenology is a commitment to represent experience 'well', all too often this is taken by medical educationalists as a mandate to retell events as they are reported by participants, instead of utilizing phenomenological inquiry to open a space of understanding. Phenomenological accounts are not always factual-they can, and often do, draw upon fictional accounts to create 'anecdotes of experience', which convey meaning that is hard to communicate using a language of facts [37]. Creating poems as part of phenomenological inquiry can be seen as a way of creating these 'anecdotes of experience'. For Van Manen, the key requirement of an 'anecdote of experience' is that the experiential account-in the case of poetic inquiry, the poem-is plausible in its truthvalue [37]. Good phenomenological writing means that the reader recognizes the plausibility of the experience, even if they have never personally experienced that moment or kind of event. This is referred to by Van Manen as 'the phenomenological nod', where the reader of an account nods in agreement as they read about the lived experience of others [38].

Poetic inquiry may also help combat the oversimplification of findings within phenomenological research, which Sass comments is a key danger of phenomenological study [39]. Phenomenologists must constantly strive against reductionist portrayal of their findings-as Kelly et al. posit 'phenomenology seeks to represent human experience in all its complexity, rather than seeking to reduce, parse or operationalize it' [40]; this can cause issues when scholars are faced with journal-mandated word counts for their qualitative research. Portraying one's data as poetry is an efficient way of displaying results within a qualitative paper's results section, without (if done carefully, as we will discuss below) succumbing to reductionism. The necessity of 'razor sharp' language in short poems can powerfully capture the human experience in fewer words than with traditional qualitative quote display [41]. As Tse suggests, poetic inquiry 'works with rather than against the complexities of experience, which researchers are always mining for understanding that is not easily extrapolated' [42]; simply put, poetic inquiry efficiently communicates a study's findings whilst conserving their complexity. Poetic inquiry may, therefore, go some way to countering the temptation of reductionism in regard to phenomenological research.

Given the alignment of poetic inquiry to hermeneutic (interpretative [43]) phenomenological traditions, and its potential to counteract some of the issues phenomenological researchers may encounter, poetic inquiry has been used within phenomenological inquiry within other branches of the academe [13, 26]. Within HPE, poetic inquiry is similarly suited to use within a phenomenological approach.

\section{Types of poetic inquiry}

One can engage in poetic inquiry in many ways. Van Luyn et al. draw distinctions between participantvoiced poetry, autobiographical poetry, and research poetry [44]. These approaches to poetic inquiry are summarized in Tab. 1. In sum, participant-voiced poetry (sometimes referred to as 'vox participare [10]', 'found poetry' [11] or 'data poetry' [45]) is the practice of creating a poem 'solely from primary sources' such as interview transcripts or written reflections [46]. The researcher shapes a participant's words, 're-present[ing]' them in poetic form [47]. Autobiographical poetry (sometimes referred to as autoethnographic poetry [45], or 'vox autobiographica [10]') is what one might expect-the construction of autobiographical poems that explore the experience of the researcher, 'in order to gain insight into a particular research process' $[44,48]$. Research poetry (or 'vox theoria [10]'), is sometimes classed as a subtype of autobiographical poetry. However, Van Luyn et al. class research poems as a distinct entity, drawing attention to the fact that they are literature-voiced poems, written specifically in response to literature or theory in a field [44]. Whilst they are created by a researcher, they are 'not a direct expression of the researcher's personal experience' [44].

\section{How to 'do' poetic inquiry}

Van Luyn et al.'s review suggests that participantvoiced poetry is the most common form of poetic inquiry [44]. There can be significant variation within this approach. Whilst we aim to cast some light on possible ways of engaging in participant-voiced poetic inquiry, the approaches we outline are by no means comprehensive or singular and are not intended to act as a prescriptive 'how-to guide'. We outline two approaches to participant-voiced poetry: 1) Glesne's method of poetic transcription and 2) Gilligan et al.'s listening guide, drawing on examples from HPE to illustrate their use.

\section{Glesne's method of poetic transcription}

We suggest Glesne's popular approach to poetic transcription [49] may act as a springboard for HPE researchers interested in poetic inquiry, by making clear 
Table 1 Types of poetic inquiry and their benefits

\begin{tabular}{ll}
$\begin{array}{l}\text { Type of poetic } \\
\text { inquiry }\end{array}$ & Description \\
$\begin{array}{l}\text { Participant-voiced } \\
\text { poetry }\end{array}$ & $\begin{array}{l}\text { Sometimes referred to as 'vox participare', } \\
\text { 'found poetry', or 'data poetry'. Created from } \\
\text { research transcripts. Researchers shape the } \\
\text { words of participants', redisplaying their own } \\
\text { words in poetic form to convey meaning. There } \\
\text { can be significant variation in the degree of } \\
\text { poetic licence taken by researchers. Some por- } \\
\text { tray participant words unchanged, in chrono- } \\
\text { logical order as they appear in transcripts; oth- } \\
\text { ers modify word order and punctuation more } \\
\text { freely, blending participant and researcher } \\
\text { voices. May involve one or multiple voices } \\
\text { Includes participatory action-research variants, } \\
\text { where researchers and participants co-con- } \\
\text { struct poems. Increasingly popular is the ap- } \\
\text { proach digital poetic inquiry, where digital text } \\
\text { is used to create found poems } \\
\text { May be used as a method of data presentation, } \\
\text { as an elicitation technique within interviews, or } \\
\text { as a method of member-checking interpreta- } \\
\text { tions with participants }\end{array}$ \\
\hline $\begin{array}{l}\text { Sometimes referred to as auto-ethnographic } \\
\text { Autobiographical }\end{array}$ \\
$\begin{array}{l}\text { poetry } \\
\text { poetry or 'vox autobiographica'. Poetry about } \\
\text { the experience of the researcher to gain insight } \\
\text { into the research process. Constructed from } \\
\text { researcher field notes or journal entries }\end{array}$
\end{tabular}

Research poetry Some have argued research poems are a form of autobiographical poetry. Many, however, consider this a separate type of poetic inquiry, which involves the creation of poetry from a field's literature base or theory. It is sometimes termed 'vox theoria'
Proposed benefits of the approach

- Preservation of participant voice, especially useful for conveying the experiences of individuals who have been previously overlooked within academic discourse. In this way, this approach can challenge dominant ideologies within a field

- Moves beyond simple description of events and experiences towards human struggles of being and becoming

- Can challenge researchers' biases and preconceived judgments of underserved populations

- Insight afforded into complex psychosocial situations and processes can engender empathy

- Emotive impact of poetic representation

- Increased accessibility of findings to wider audiences

- Poetic inquiry is a method of embodied interpretation. In all its forms, writing helps researchers find out more about themselves and their topic of inquiry. Autobiographical poetry, in particular, can aid researcher reflexivity, and advance the development of new approaches or methods

\section{Examples of research employing approach}

Brown CS. The use of poetry in qualitative post-hoc analysis. J Poet Ther. 2018;31:107-12

MacNeil C. The prose and cons of poetic representation in evaluation reporting. Am J Eval 2000, 21:359-67

Poindexter CC. Research as poetry: A couple experiences HIV. Qual Inq. 2002;8:707-14 
doctors who had recently crossed the threshold into clinical practice [50]. As Glesne recommends, we were attentive to participant syntax-during our re-readings we made detailed notes in the margins of each transcript concerning participant tone, emphasis, use of pauses, rhythm and syntax. We also reviewed each transcript for repeating words, phrases, and expressions. An example of our process is depicted within the Table S1 of the Electronic Supplementary Material, where one participant-voiced poem ('Friends are everything') is displayed alongside the section of original transcript from which it is drawn. Words and phrases utilized in the poem are underlined.

\section{Gilligan et al.'s 'Listening Guide' method}

Gilligan et al. developed the 'Listening Guide' method in 2003 as a way of paying particular focus to how participants talk about themselves (using their first person 'voices')[51]. This method involves creation of a type of participant-voiced poetry, which helps researchers consider participant identities and subjectivities [52]. The method encourages researchers to pay close attention to participant use of the personal pronoun 'I' and recommends the creation of 'Ipoems' in the second phase of the listening method [52]. The steps of the listening guide method are detailed in Tab. 2. Typically, I-poems are utilized only in the data analysis phase of the listening guide method [52], though some authors have used them to display results [53]. For examples of I-poems, we recommend interested authors review the following references [51-55].

It is important to clarify that participant-voiced poetic inquiry is, by nature, an inductive approach to data analysis. If researchers wish to use educational theory to inform their analysis of participant-voiced poems, we suggest they do so in a way which aligns with what Varpio et al. term a 'subjectivist inductive' orientation to theory and research, where researchers work 'from data up to abstract conceptualizations'
[56]. One subjectivist inductive approach to theory, which Varpio et al. term 'theory-informing inductive data analysis' may be of particular use to authors interested in applying theory to the process of poetic inquiry. In this approach, researchers move from data to theory, starting out with the intent to 'understand or explain a ... phenomenon', and later using theory as 'an interpretative tool' to make sense of created participant-voiced poems [56]. In their study of the experience of women who identify as lesbian, gay, or queer, Lambert uses Butler's theory of passionate attachments to analyze a poem created from participant interview text, employing theory in such a 'theory-informing inductive data analysis' approach [57].

Though we have outlined two specific approaches to poetic inquiry, we encourage researchers to read widely, and to adapt the method of poetic inquiry they select to suit their context and study, if appropriate. Transparency of one's methodological approach is key, and adaptors must ensure they adequately detail their process, and justify the steps they have taken. There is an ethical domain to participant-voiced poetry, and it is important that researchers define and hold themselves to a set of principles throughout the process of inquiry [58].

\section{Poetizing HPE qualitative research}

We envision that increasing participant-voiced poetry use within HPE research could add depth to research questions which concern how participants speak about, and perceive, themselves, others, and their experiences. Through inviting researchers to engage deeply with participant accounts, poetic inquiry within HPE is not just a tool, but a way of being that gives rise to the space for wonder, surprise, emotions and creative expression and interpretation.

Though the benefits of poetry may appeal, researchers may not wish, or have capacity to, dive head-first into the unknown waters of poetic inquiry. If this is the case, there are several ways in which

Table 2 Steps of the listening guide. Complied using information from [51, 54, 55]

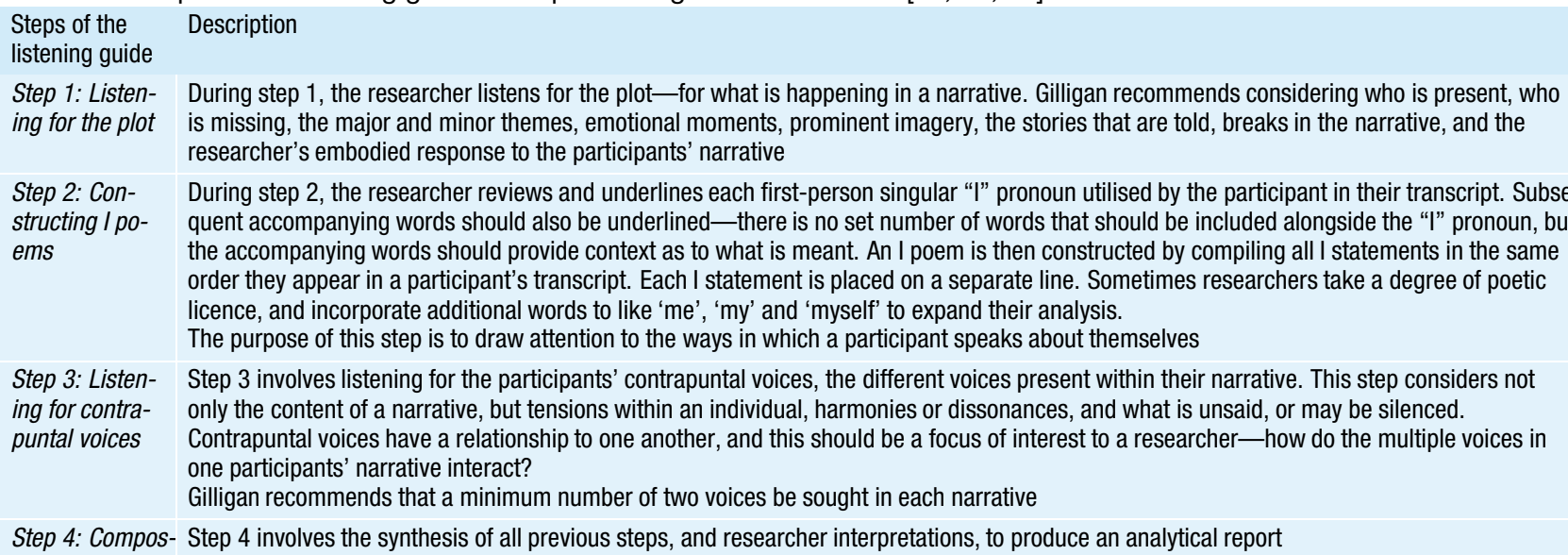

Step 4: Compos- Step 4 involves the synthesis of all previous steps, and researcher interpretations, to produce an analytical report
ing an analysis 
one can engage in 'methodological borrowing' [59] to poetize more traditional qualitative research projects and develop as a poet gradually over time [60]. Reflexive and analytic journaling is common within qualitative research. Researchers could expand this practice to include poetic journaling, an approach where researchers begin to think poetically about their findings. No two poetic journals will look the same. Researchers may wish to read poetry, taking notes on impactful lines and phrases which make them think. Researchers may also begin to write poems about their data and position as a researcher, experimenting with participant phrases, their own thoughts, and poetic conventions like rhyme and form. Keeping a poetic journal may also help capture what the sociologist Mills terms 'fringe thoughts'-ideas which are by-products of everyday life, and which we usually dismiss as 'mental noise' but can hold intellectual value relevant to data analysis and theorization, as they prompt us to think differently about our research [61]. Excerpts from poetic journals could also be included within research manuscripts to demonstrate the process of reflexive engagement researchers have undertaken throughout a project. Using Gilligan's listening guide as part of one's analysis, but not results representation, may help researchers begin to think poetically about their data, and develop their poetic ear, without fear of their poetic output being subject to wide scrutiny.

\section{Considerations of quality}

There is debate within the poetic inquiry community as to what qualifies one to use poetic inquiry, with some concluding that, to engage in poetic inquiry, one should be a published or formally trained poet in their own right [58]. Respectfully, we disagree. Though proponents may claim their views are to protect the reputation of poetry, and ensure quality inquiry, such views position poetry as an elitist pursuit which prevents the engagement of novice, but keen, would-be poetic researchers. Given the benefits of poetic inquiry, we join with Lahman and Richard in advocating for 'good enough' research poetry [62]. 'Good enough' poetry is the space between the belief that 'any person may write poetry' (we recognize you need a grounding in poetic inquiry, and an appreciation of the approach), and 'the scholarly belied that in-depth training is needed' [62].

This debate may leave you feeling uneasy. As health professions educators, we enjoy practical guidance. If you are wondering how you will know whether your poems are 'good enough', we suggest you turn to Sullivan's 2009 architectural dimensions of a poem [63] for reassurance, which Pate has synthesized into a quality checklist [26] (summarized in Table S2 of the Electronic Supplementary Material). As previously, these are not the only markers of poetic quality, nor do we believe they should be used prescriptively. Sulli- van's dimensions interplay and exist as a complex web or nexus that influence the impact and resonance of a poem. We advise that where researchers wish to use this checklist, they frame it as a broad guide or reflexive tool to consider the steps taken within their own research projects carefully and critically. Additionally, as researchers open up the possibilities of the method, it may be beneficial to learn more about typical poetic conventions such as form, meter and rhyme to advance your craft-but this is no means a prerequisite, at least in our eyes, to the ability to produce 'good enough' participant-voiced poetry.

\section{Concluding thoughts}

Though qualitative research is increasingly valued, barriers still exist to the progression of qualitative research within HPE. Discussions of the quality of qualitative research have centered methodological rigor, an important concern, but one that has dominated conversation. The threat to qualitative creativity has been much less frequently discussed within HPE. Poetic inquiry has not been a central topic of conversation yet holds the potential to encourage researchers to think deeply and creatively about their findings. Poems emphasize language and may cast new light on areas of HPE where thinking has become narrowed. Poetic inquiry can foster increased researcher attention to reflexivity in a creative and contemplative way. Crucially, poetic inquiry can preserve participant voice within research reports, and may offer one way to represent experience more faithfully. Poetic inquiry has much to offer HPE, and we encourage researchers to take up the poetic mantle to diversify research within the field and cultivate creativity. For, to return to the words of the poet Thomas Grey, who would not wish their thoughts to breathe, and words to burn?

Acknowledgements The authors would like to thank Professor Tim Dornan for his encouragement, and for suggesting they connect over their mutual love for poetry and phenomenology.

\section{Funding No funding}

Conflict of interest M.E. L. Brown, M. Kelly and G.M. Finn declare that they have no competing interests.

Open Access This article is licensed under a Creative Commons Attribution 4.0 International License, which permits use, sharing, adaptation, distribution and reproduction in any medium or format, as long as you give appropriate credit to the original author(s) and the source, provide a link to the Creative Commons licence, and indicate if changes were made. The images or other third party material in this article are included in the article's Creative Commons licence, unless indicated otherwise in a credit line to the material. If material is not included in the article's Creative Commons licence and your intended use is not permitted by statutory regulation or exceeds the permitted use, you will need to obtain permission directly from the copyright holder. To view a copy of this licence, visit http://creativecommons.org/licenses/by/4.0/. 


\section{References}

1. Foley J. How to read an oral poem. Chicago: University of Illinois Press; 2002.

2. Havelock E. Review: the ancient art of oral poetry. Philos Rhetor. 1979;12:187-202.

3. Lacoue-Labarthe P. Poetry as experience. Stanford: Stanford University Press; 1999.

4. Wolters F, Wijnen-Meijer M. The role of poetry and prose in medical education: the pen as mighty as the scalpel? Perspect MedEduc. 2012;1:43-50.

5. Muszkat M, Yehuda A, Moses S, Naparstek Y. Teaching empathy through poetry: a clinically based model. Med Educ. 2010;44:503.

6. Finn G, Brown M, Laughey W. Holding a mirror up to nature: the role of medical humanities in postgraduate primary care training. Educ Prim Care. 2021;32:73-7.

7. Vincent A. Is there a definition? Ruminating on poetic inquiry, strawberries and the continued growth of the field. ArtRes Int Transdiscipl J.2018;3:48-76.

8. Wu B. My poetic inquiry. Qual Inq. 2021;27:283-91.

9. Faulkner S. Poetic inquiry: craft, method and practice. New York: Routledge; 2019.

10. Prendergast $M$. The phenomenon of poetry in research. "Poem is what?" Poetic inquiry in qualitative social science. In: Prendergast M, Leggo C, Sameshima P, editors. Poetic inquiry: vibrant voices in the social sciences. Rotterdam: Sense;2009. pp. 19-21.

11. SjollemaS, HordykS, Walsh C, HanleyJ, Ives N. Found poetry - finding home: a qualitative study of homeless immigrant women. J Poet Ther. 2012;25:205-17.

12. Eisner E. The enlightened eye. NewYork: Macmillan; 1991.

13. Freeman M. "Between eye and eye stretches an interminable landscape": the challenge of philosophical hermeneutics. Qual Inq. 2001;7:646-58.

14. Fitzpatrick E, Fitzpatrick K. What poetry does for us in education and research. In: FitzpatrickE, FitzpatrickK, editors. Poetry, method and education research: doing critical, decolonising and political inquiry. Oxon: Routledge; 2020.

15. Nichols T, Biederman D, Gringle M. Using research poetics "responsibly": applications for health promotion research. Int Q CommunityHealth Educ. 2014;35:5-20.

16. Schwandt $T$. Three epistemological stances for qualitative inquiry: interpretativism, hermeneutics and social constructionism. In: Denzin N, Lincoln Y, editors. The landscape of qualitative research: theories and issues. Thousand Oaks: SAGE; 2003. pp. 292-331.

17. Kiger M, Varpio L. Thematic analysis of qualitative data: AMEE guide No. 131. Med Teach. 2020;42:846-54.

18. Vaismoradi M, Jones J, Turunen H, Snelgrove S. Theme development in qualitative content analysis and thematic analysis. J Nurs Educ Pract. 2016;6:100-10.

19. Neubauer B, Witkop C, Varpio L. How phenomenology can help us learn from the experiences of others. Perspect Med Educ. 2019;8:90-7.

20. MacLure M. Classification or wonder? Coding as an analytic practice in qualitative research. In: Coleman R, editor. Deleuze and research methodologies. Edinburgh: Edinburgh University Press;2013. pp. 164-83.

21. MacLure M. The wonder of data. Cult Stud Crit Methodol. 2013;13:228-32.

22. Kleiman S. Phenomenology: to wonder and search for meanings. Nurse Res. 2004;11:7-19.

23. Janesick V. Intuition and creativity: a pas de deux for qualitative researchers. Qual Inq. 2001;7:531-40.

24. Bothe A, Andreatta R. Quantitative and qualitative research paradigms: thoughts on the quantity and the cre- ativity of stuttering research. Adv Speech Lang Pathol. 2004;6:167-73.

25. Veen M, Cianciolo A. Problems no one looked for: philosophical expeditions into medical education. Teach Learn Med. 2020;32:337-44.

26. Pate J. Found poetry: poetizing and the 'art' of phenomenological inquiry. SAGE Res Methods Cases. 2014; https://doi. org/10.4135/978144627305013512954.

27. StapletonSR. Data analysis in participatory action research: using poetic inquiry to describe urban teacher marginalization. Action Res. 2021;19(2):449-71.

28. Rapport F, Hartill G. Making the case for poetic inquiry in health services research. In: Galvin KT, Prendergast M, editors. Poetic inquiry II - seeing, caring, understanding. Rotterdam: BrillSense;2016. pp.211-26.

29. ÖhlénJ.Evocation of meaningthrough poetic condensation of narratives in empirical phenomenological inquiry into human suffering. Qual Health Res. 2003;13:557-66.

30. Wiebe N. Mennocostal musings: poetic inquiry and performance in narrative research. Forum Qual Soc Res. 2008;9(2):42.

31. Anderson T. Through phenomenology to sublime poetry: Martin Heidegger on the decisive relation between truth and art. Res Phenomenol. 1996;26:198-229.

32. Bruns G. Heidegger's estrangements. Language, truth, and poetry in the later writings. New Haven: Yale University Press; 1989.

33. Freshwater D. The poetics of space: researching the concept of spatiality through relationality. Psychodyn Pract. 2005;11:177-87.

34. Heidegger M. Being and time. Albany: Suny Press; 2010.

35. Koskela J. Truth as unconcealment in Heidegger's Being and Time. Minerva. 2012;16:116-28.

36. Galvin K, Todres L. Research based empathic knowledge for nursing: a translational strategy for disseminating phenomenological research findings to provide evidence for caring practice. Int J Nurs Stud. 2011;48:522-30.

37. Van Manen M. Philological methods: the vocative. Phenomenology of practice: meaning-giving methods in phenomenological research and writing. Walnut Creek: Left CoastPress; 2014. pp. 240-81.

38. Van Manen M. Researching the lived experience: human science for an action sensitive pedagogy. London: University of Western Ontario; 1997.

39. Sass L. Three dangers: phenomenological reflections on the psychotherapy of psychosis. Psychopathology. 2019;52:126-34.

40. Kelly M, Svrcek C, King N, Scherpbier A, Dornan T. Embodying empathy: a phenomenological study of physician touch. Med Educ. 2020;54:400-7.

41. Leavy P. Method meets art: arts-based research practice. NewYork: Guilford; 2020.

42. Tse V. A review of poetic inquiry: vibrant voices in the social sciences. Education. 2014;20:177-81.

43. Bynum W, Varpio L. When I say ... hermeneutic phenomenology. MedEduc. 2017;52:252-3.

44. van Luyn A, Gair S, Saunders V. 'Transcending the limits of logic': poetic inquiry as a qualitative research method for working with vulnerable communities. In: Gair S, van Luyn A, editors. Sharing qualitative research: showing lived experience and community narratives. New York: Routledge; 2016. pp.95-111.

45. Willis K, Bishop E. "Hope is that fiery feeling": using poetry as data to explore the meanings of hope for young people. Forum Qual Soc Res. 2014;15:9.

46. Connelly K. 'What body part do I need to sell?': Poetic re-presentations of experiences of poverty and fear from 
low-income Australians receiving welfare benefits. Creat Approaches Res. 2010;3:16.

47. Gair S, Van Luyn A. Sharing qualitative research: showing lived experience and community narratives. New York: Routledge; 2016.

48. Furman R, Langer C, Davis C, GallardoH, KulkarniS. Expressive, research and reflective poetry as qualitative inquiry: a study of adolescentidentity. Qual Res. 2007;7:301315.

49. Glesne C. That rare feeling: re-presenting research through poetic transcription. Qual Inq. 1997;3:202-21.

50. Brown ME, Proudfoot A, Mayat NM, Finn GM. A phenomenological study of new doctors' transition to practice, utilising participant-voiced poetry. Adv Health Sci Educ Theory Pract. 2021; https://doi.org/10.1007/s10459-02110046-X.

51. Gilligan C, Spencer R, Weinberg M, Bertsch T. On the listening guide: a voice centred relational method. In: Camic PM, Rhodes JE, Yardley L, editors. Qualitative research in psychology: expanding perspectives in methodology and design. Washington, DC: American Psychological Association;2003. pp. 157-72.

52. Edwards R, Weller S. I-poems as a method of qualitative interview data analysis: young people's sense of self. London: SAGE; 2015.

53. Balmer D, Devlin M, Richards B. Understanding the relation between medical students' collective and individual trajectories: an application of habitus. Perspect Med Educ. 2017;6:36-43.
54. Petrovic S, Lordly D, Brigham S, Delaney M. Learning to listen: an analysis of applying the listening guide to reflection papers. Int Jual Methods. 2015;14:1609406915621402.

55. Gilligan C, Eddy J. Listening as a path to psychological discovery: an introduction to the listening guide. Perspect MedEduc. 2017;6:76-81.

56. Varpio L, Paradis E, Uijtdehaage S, Young M. The distinctions between theory, theoretical framework, and conceptual framework. Acad Med. 2020;95:989-94.

57. Lambert K. 'Capturing' queer lives and the poetics of social change. Continuum. 2016;30:576-86.

58. Owton H. Doing poetic inquiry. London: Palgrave Macmillan; 2017.

59. Varpio L, Martimianakis M, Mylopoulos M. Qualitative research methodologies: embracing methodological borrowing, shifting and importing. In: Cleland J, Durning S, editors. Researching medical education. 1st ed. Chichester, WestSussex: Wiley; 2015.

60. Cahnmann M. The craft, practice, and possibility of poetry in educational research. Educ Res. 2003;32:29-36.

61. Mills C. The sociological imagination. Oxford: Oxford University Press; 2000.

62. Lahman M, Richard V. Appropriated poetry. Qual Inq. 2013;20:344-55.

63. Sullivan A. Defining poetic occasion in inquiry: concreteness, voice, ambiguity, emotion, tension and associative logic. Poetic inquiry, vibrant voices in the social sciences. Rotterdam: BrillSense;2009. pp. 111-26. 